\title{
O LIVRO DIDÁTICO DE HISTÓRIA: ESCOLHAS, USOS E PERCEPÇÕES DE PROFESSORES E ALUNOS NO COTIDIANO ESCOLAR
}

\author{
Isaide Bandeira da Silva*
}

\begin{abstract}
RESUMO
O livro didático faz parte da cultura material da maioria das escolas públicas brasileiras por meio do Programa Nacional do Livro Didático. Sendo assim, um dos objetivos pesquisados foi identificar e analisar o processo de escolha dos livros didáticos no Estado do Ceará, relacionando-o com os usos que se faz deste instrumento no cotidiano. Tivemos como espaço de pesquisa quatro escolas públicas; em cada escola, uma turma de $6^{\circ}$ ano. Como parte do procedimento metodológico, realizamos entrevistas, questionários e observação direta durante as aulas de História do ano de 2008. Finalizamos com uma "roda de conversa". Utilizamos como categoria de análise o conceito de "apropriação", de Chartier, as categorias de "estratégias e táticas", de Certeau, o conceito de "cultura escolar" cunhado por Julia. Percebemos que, em geral, apenas o texto principal de cada capítulo é trabalhado. Então, apesar das transformações teóricas e gráficas na produção do livro didático, este é subutilizado.
\end{abstract}

Palavras-chaves: Livro Didático. Programa Nacional do Livro Didático. Ensino de História.

\begin{abstract}
The school textbook is part of the material culture of most public Brazilian schools by means of National Textbook Program. This research aimed at identifying and analyzing textbooks choice in Ceara, relating it to the uses of such tool within school daily life. The setting for the study was four public schools, in the 6th grade. As part of methodology, public managers were interviewed, teachers answered surveys, and a direct observation during History classes in 2008 school year was carried out.
\end{abstract}

\footnotetext{
* Doutora em Educação pela Universidade Federal do Rio Grande do Norte (UFRN). Professora Efetiva de Ação Educativa Patrimonial do Curso de História da Faculdade de Educação, Ciências e Letras do Sertão Central/Universidade Estadual do Ceará (UECE). E-mail: isaidebandeira@hotmail.com
} 
The observation was over after round chats with students in the class. Chartier's concept of "appropriation" was an analysis category, as well as de Certeau's "strategy and tatics", and Julia"s concept of "school culture". The study concludes that only the main text of each chapter is really worked in daily class practice. Therefore, although theoretical and graphic changes in textbook production, the textbook is underused.

Keywords: Textbook. National Textbook Program. History teaching.

\section{Introdução: o percurso da pesquisa}

Difícil fotografar o silêncio.

Entretanto tentei. (...)

Tinha um perfume de jasmim

no beiral de um sobrado.

Fotografei o perfume.

(BARROS)

O livro didático é um produto complexo, porque entrecruza diferentes perspectivas teóricas, editoriais, pedagógicas, mercadológicas, políticas e ideológicas, e por isso, principalmente na transição dos séculos XX e XXI, tem despertado tantas críticas favoráveis e desfavoráveis, e a cada dia ocupa mais espaço tanto na cultura escolar de inúmeras salas de aulas espalhadas pelo Brasil quanto nas pesquisas acadêmicas. Assim, é fundamental sabermos como este livro é escolhido e trabalhado no cotidiano da sala de aula e como podemos relacioná-lo às práticas pedagógicas do cotidiano de professores e alunos.

Nesta perspectiva, conforme Sposito (2006, p. 46), há necessidade de pesquisas que visem compreender o cotidiano escolar, se respaldando numa abordagem qualitativa, para, então, diminuir o "distanciamento entre três momentos cruciais da política sobre as questões relacionadas aos materiais didáticos para o sistema educacional: os processos de avaliação, de escolha e de uso dos livros (...)." Também Oliveira et al. (2007, p. 63) destacaram que a "íntima relação governamental e escolar puseram em foco o debate acerca de alguns aspectos, como a relação do Livro Didático 
com o papel do professor no processo de escolhas e usos deste instrumento pedagógico em sala de aula".

Esse artigo, portanto, é uma apresentação sintética de nossa pesquisa desenvolvida no Doutorado do Programa de Pós-Graduação em Educação da Universidade Federal do Rio Grande do Norte (UFRN), que culminou na tese intitulada "o livro didático de história: um caleidoscópio de escolhas e usos no cotidiano escolar (Ceará, 2007-2009)".

A pesquisa aconteceu em quatro escolas públicas, duas estaduais e duas municipais, em duas cidades: Fortaleza e Quixadá., e em cada escola, uma turma de $6^{\circ}$ ano diurno. Os procedimentos técnicos de aquisição de dados foram a realização e a transcrição de entrevista semiestruturada com 14 gestores das Secretarias de Educação do Estado e dos Municípios de Fortaleza e Quixadá; a observação direta do processo de escolha dos livros didáticos nos dois municípios; a observação direta das aulas de história das quatro turmas durante todo o ano letivo de 2008; os livros didáticos de História adotados nas quatro turmas; pareceres, resoluções e portarias do Ministério da Educação com relação ao processo de escolha dos livros didáticos; o edital do Programa Nacional do Livro Didático (PNLD)/2008 e o Guia de Livros Didáticos do PNLD/2008; os Projetos Políticos Pedagógicos (PPP) das escolas pesquisadas (ou um documento que o substitui, denominado Gestão Integrada da Escola - GIDE); formulários de caracterização das escolas e as anotações feitas nos Diários de Campo das turmas observadas no decorrer do ano letivo de 2008 e os dados obtidos na realização de Rodas de conversa, como desenhos e frases com os alunos de cada turma.

Na sistematização da pesquisa, analisamos os dados a partir da sua classificação, organização e estabelecimento de relações, visando a uma reflexão no que diz respeito à ligação entre os processos de escolhas e os usos dos livros didáticos de História no cotidiano escolar.

\section{Objetivos e metodologia}

Objetivamos compreender as escolhas e usos do livro didático de história na tessitura da escola e da sala de aula para a construção das práticas pedagógicas relacionadas, sem, entretanto, desconsiderar a totalidade 
social na qual a esfera escolar está envolvida (ANDRÉ, 1991). Desta forma, salientamos como objetivos expressos: perceber e analisar os processos de escolhas dos livros didáticos de História no Ceará, relacionando-os com os usos do livro didático de História no cotidiano das escolas públicas por professores e alunos.

Diante deste panorama, fomos movidos por algumas problemáticas, dentre elas: como acontece o processo de escolha dos livros didáticos de História nas escolas da rede pública do Ceará? Que tipo de avaliação é feita pelo professorado ao escolher o livro didático? O Guia de Livros Didáticos/ PNLD é consultado? Caso afirmativo, como? É possível caracterizar as diferentes utilizações do livro didático em sala de aula? Que práticas escolares, professores e alunos estão fazendo com os livros didáticos de História nas inúmeras salas de aula das escolas públicas?

Em junho de 2007, fizemos o acompanhamento das escolhas dos livros didáticos para o triênio de 2008-2010 das quatro escolas selecionadas para a pesquisa, para entender como se dava esse processo na prática. No segundo semestre de 2007, realizamos entrevistas ${ }^{1}$ semiestruturadas com perguntas abertas ${ }^{2}$, para identificar as orientações do Governo do Estado do Ceará e das Prefeituras de Fortaleza e Quixadá no que diz respeito à escolha dos livros didáticos, frente à orientação geral do Governo Federal pelas resoluções e portarias que regulamentam esse processo.

As pessoas entrevistadas foram escolhidas conforme o cargo que assumiam na época: como as duas secretárias de educação dos municípios participante da pesquisa, técnicas de cada Coordenadoria Regional de Educação (CREDE) do Estado presente nas duas cidades e técnicas das Secretarias Municipais de Educação responsáveis pelo acompanhamento do processo de escolha dos livros didáticos junto às escolas. Durante o ano de 2008, entrevistamos as quatro professoras de História das salas de aula que acompanhamos e as coordenadoras ou supervisoras pedagógicas

${ }^{1}$ Conforme Lüdke (1986), trata-se de uma das principais técnicas de trabalho em quase todos os tipos de pesquisa utilizados nas ciências sociais, pois pela interação entre entrevistador e entrevistado; "permite a captação imediata e corrente da informação desejada" (p. 34).

2 "que exigem uma resposta pessoal, espontânea, com todos os pormenores e restrições que o próprio informante considere necessário" (GRESSLER, 1989, p. 72). 
dessas escolas, perfazendo ao todo 14 (catorze) entrevistas gravadas e transcritas.

Usamos os nomes reais de todas as pessoas que participaram desta pesquisa, que permitiram e assinaram as autorizações. Desta feita não tivemos o intuito de homogeneizar nenhuma situação exposta e analisada e nem de julgar qualquer declaração ou comportamento, pois a finalidade não foi dizer o certo ou errado na condução do processo de escolha e usos do livro didático no cotidiano escolar, mas buscar compreendê-los dentro de contextos específicos. Partimos do pressuposto de que não basta ser um livro aprovado pelo PNDL e constar no GID para ser bem utilizado/ explorado em suas potencialidades.

No início do ano de 2008, junto com a coordenação/supervisão pedagógica e a professora de história do ensino fundamental de cada escola, vimos o calendário de aulas para definir o dia $^{3}$ e a turma (A, B, $\mathrm{C}$ ou D) do $6^{\circ}$ ano que participaria da pesquisa. Escolhemos essa turma por ser a primeira série do ensino fundamental II, quando se supõe que será o primeiro contato direto com um professor formado em História e, ainda, porque, na maioria das vezes nesta série, o conteúdo de História é relacionado à Idade Antiga, o que requer, em tese, uma maior utilização do livro didático, pois outras fontes para se trabalhar com esse assunto ainda são pouco acessíveis para os professores em geral, embora, de acordo com Funari (2003), haja muitas fontes acessíveis hoje para se trabalhar com história antiga em qualquer nível de ensino ${ }^{4}$.

Ressaltamos que, no início, a pretensão era observar cada turma somente por dois bimestres letivos, entretanto, quando em campo, percebemos que, para obter uma melhor percepção e reafirmar os usos já percebidos,

3 Conforme nossa disponibilidade para estar em Quixadá e em Fortaleza na mesma semana, assim teria que ser em dias diferentes.

4 “Os livros didáticos também foram afetados pela profissionalização do estudo da Antiguidade no país. Cada vez mais, os livros tratam não só dos temas e das explicações historiográficas tradicionais, mas procuram diversificar os objetos e as abordagens, assim como inserir o estudo da Antiguidade na realidade brasileira. (...). Para uso com os alunos de ensino fundamental e médio, há a coleção da editora Atual (http://www.editorasaraiva. com.br), História geral em documentos, onde se encontram textos e documentos materiais e iconográficos comentados para uso em sala de aula, sobre Grécia (Teresa van Acker) e Roma (Pedro Paulo Funari)" (FUNARI, 2003, p. 97 e 104). 
seria melhor continuar a observação direta durante o ano letivo todo, tendo claro que não era uma busca ocasional, mas "posta a serviço de um objeto de pesquisa, questão ou hipótese, claramente explicitado" (LAVILLE e DIONNE, 1999, p. 176), ou seja, para melhor captar, analisar e interpretar os usos de professores e alunos referentes aos livros didáticos de História no cotidiano escolar. Assim, com a permissão das professoras, ficamos em locus nas quatro turmas nas aulas de História durante todo o ano de 2008.

É importante destacar que, com relação à metodologia da observação direta, Lüdke (1986, p. 27) salienta algumas críticas: "primeiramente por provocar alterações no ambiente ou no comportamento das pessoas observadas. Outra crítica é a de que este método se baseia muito na interpretação pessoal". Entretanto, esta mesma autora ressalta que alguns teóricos refutam estas críticas e se baseia em Bogdan e Biklen para citar: "Los observadores quedaron convencidos de que su presencia en el aula no influía sobre la enseñanza." (LÜDKE, 1986, p. 153).

Destacamos que o tempo de permanência no campo observado faz toda diferença, "enquanto nas pesquisas antropológicas o mínimo é 6 meses a vários anos, na educacional pode variar de 6 semanas a 3 anos. E ainda é necessário, estabelecer os limites do que se deve observar."(GRESSLER, 1989, p. 89). Conforme, Bogdan e Biklen (1994), uma presença estranha no início altera sim o ambiente, mas depois, com o tempo, há uma assimilação desse ser estranho no ambiente. Então, como ficamos durante o ano letivo todo, sentimos que logo após as primeiras semanas os alunos já não mais se intimidavam com nossa presença, inclusive aos poucos foram percebendo que não éramos realmente mais uma professora para eles, e sim estávamos fazendo um trabalho da faculdade, portanto, com o passar dos dias, foram agindo de forma mais espontânea na sala de aula e assim brincavam e brigavam independente de nossa presença na sala. Esta realidade também foi comprovada por Costa (1997, p. 31), em sua pesquisa: "Estou certa de que minha presença não alterou a dinâmica da sala de aula nem tampouco o comportamento de professores e alunos." Da mesma forma revelou Oliveira (2006, p. 197), em sua tese de doutorado: "Quanto mais tempo fiquei em sala

5 Tradução livre da autora: "Os observadores ficaram convencidos de que sua presença na sala não influenciava o ensino". 
de aula, mais minha presença foi sendo assimilada pela professora e pelos alunos e foi se estabelecendo uma relação de confiança mútua...".

Utilizamos como suporte teórico para melhor analisar e interpretar as fontes de forma sistemática, o conceito de "apropriação" de Chartier (1990), tendo em vista que este conceito está voltado para identificar as representações que são feitas da recepção de algum objeto cultural, no caso, o livro didático. A representação de Chartier parte do conhecimento prévio e não do senso comum coletivo, pois as realidades são dadas à leitura conforme diferentes contextos, classificações, determinações, apropriação do conhecimento que faz representar algo.

Desta forma, para nós, o conceito de "apropriação" equivale ao "uso" do livro didático, pois, na pesquisa que fizemos nas quatro salas de aula, buscamos revelar os múltiplos significados dos usos do livro didático de história durante as aulas semanais de história, o que nos levou a fazer uma analogia com o caleidoscópio que a cada momento que é usado, emite diferentes imagens. Consideramos que, com Chartier (1988, p. 26), “A apropriação, tal como a entendemos, tem por objectivo uma história social das interpretações, remetidas para as suas determinações fundamentais (que são sociais, institucionais, culturais) e inscritas nas práticas específicas que as produzem".

Ainda trabalhamos com o conceito de "cultura escolar" cunhado por Dominique Julia (2001, p. 9), que afirma: "poder-se-ia descrever a cultura escolar como um conjunto de normas que definem conhecimentos a ensinar e conduta a inculcar, e um conjunto de práticas que permitem a transmissão desses conhecimentos e a incorporação desses comportamentos".

Também utilizamos os conceitos de "estratégias e táticas" de Certeau (1994), principalmente relacionadas ao livro didático em meio às práticas pedagógicas, pois, de acordo com este autor, não há consumo passivo, visto que no cotidiano existem inúmeras maneiras de fazer uso de algo material. Percebemos as "estratégias e táticas" tanto no que se refere ao processo de escolha dos livros didáticos quanto na prática escolar de cada sala de aula observada nas ações relacionadas ao livro didático.

De acordo com Certeau (1994, p. 47), "as estratégias escondem sob cálculos objetivos a sua relação com o poder que os sustenta, guardado 
pelo lugar próprio ou pela instituição". No caso de nossa investigação, isto se dá pelo espaço institucional que a professora ocupa em sala de aula, porém este mesmo autor faz questão de ressaltar o valor das "táticas" que, segundo ele, são inevitáveis. Apesar de considerá-las "arte do fraco", o autor afirma também que é antes uma característica da astúcia própria ao ser humano, que bem sabe fazer uso das brechas e, assim, torna-se forte diante das circunstâncias. O que por diversas vezes aconteceu nas salas de aula observadas pelas atitudes dos alunos, uma "arte de dar golpes no campo do outro" (CERTEAU, 1994, p. 48), de forma sutil e eficaz, mas mostrando-se sujeitos apesar de algumas vezes não serem considerados como tais. Podemos adiantar como exemplo, que as orientações iniciais que as professoras davam a cada aula, como resumo ou questionários, eram "estratégias" de ação para cumprir o calendário escolar, mas, à medida que a aula ia acontecendo, os alunos utilizavam "táticas", por exemplo, quando eram solicitados a fazer determinada atividade e logo se agrupavam em dupla ou trio sem a professora ter solicitado, ou as deixavam para fazer em casa, uma vez que seriam cobrados somente na próxima aula.

\section{O processo de escolha do livro didático no Ceará}

Na possibilidade de melhor compreendermos a tessitura da escola e da sala de aula na construção das práticas pedagógicas no ensino de História, em especial relacionadas às escolhas e aos usos do livro didático, é importante considerar o que pensam os diferentes sujeitos do espaço escolar, como professores e alunos.

\subsection{Diferentes percepções sobre o livro, o PNLD e o Guia: vantagens, dificuldades e perspectivas para a escolha}

Ao abordarem sobre as mudanças de perspectivas da feitura e uso do livro na sociedade europeia entre os séculos XVI e XIX, Chartier e Roche (1995, p. 111) afirmaram: "Objeto de inesgotável riqueza, o livro exerce há muito sua fascinação". Esta afirmação se confirma também no Brasil, conforme Hallewell (1985) tanto no decorrer dos séculos XIX e XX. Ainda no início do século XXI, podemos perceber essa fascinação 
na seguinte frase dita por uma aluna da turma do $6^{\circ}$ ano da EEF Nemésio Bezerra: "Meu livro é um mundo de magia".

No que diz respeito à produção ${ }^{7}$ desse material, Johnsen (1996, p. 24) nos lembrou que os livros didáticos são um tipo de literatura complexa e compilada por várias partes interessadas (especialistas, autores, editores, autoridades), "y tienen la intención de servir a diversos grupos de usuários (maestros, estudiantes/alumnos, padres). Las motivaciones no son las mismas para cada grupo ${ }^{8}$ ". Desta forma, aclaram-se os diferentes agentes sociais que tem o livro didático como parte do seu métier, por isso, é importante a compreensão de que este objeto produzido fora da escola "sofre alterações específicas advindas de sua própria materialidade e do seu lugar de produção, para além daqueles elementos ligados aos imperativos didáticos" (COELHO, 2005, p. 242).

Neste cenário, é pertinente a afirmação de Gatti Júnior (2004, p. 26) de que o livro didático desempenha "este papel central no cotidiano escolar dos alunos há tempos e, no caso brasileiro, por que não mencionar, no exercício profissional dos educadores dos mais diferentes níveis...". Com relação ao Ceará, podemos desde já adiantar que o reconhecimento do valor do livro didático na vida dos professores e alunos, no cotidiano da sala de aula, é perceptível pelas falas das pessoas entrevistadas para esta pesquisa. São emblemáticas as afirmações como a que foi feita pela secretária de educação de Quixadá: "Nada substitui o livro didático! O computador, as coleções de paradidático, o cd, o DVD, tudo é uma somatória, que vem favorecer o trabalho do professor." Esta opinião é similar à da secretária de educação de Fortaleza:9 "O livro é o livro, nada o substitui!".

6 Fonte: "Roda de Conversa" realizada pela autora em dez./2008.

7 “A escala industrial tomada pela produção didática em História, no final da década de 1990, contribuía para que ao trabalho do autor individual fossem agregados ao trabalho de outros profissionais que faziam com que a qualidade do texto, das ilustrações, do grafismo, melhorasse sobremaneira, sendo possível afirmar, desse modo, que se tratava mais de uma equipe responsável pelo produto editorial do que da expressão única da idéia de um autor" (GATTI, 2004, p. 236).

8 Tradução livre da autora: "e têm a intenção de servir a diversos grupos de usuários (professores, estudantes/alunos, pais). As motivações não são as mesmas para cada grupo".

9 Entrevista concedida à autora em 09 de agosto de 2007, no seu gabinete na SME de Fortaleza. 
Em meio à abertura política e à redemocratização nacional nos anos de 1980, foi criado o Programa Nacional do Livro Didático (PNLD), pelo Decreto n. 91.542, de 19 de agosto de 1985, tendo como função avaliar, indicar, comprar e distribuir livros didáticos para as escolas públicas. Uma década depois, "o PNLD reconfigurou-se, por meio de um processo de avaliação em que uma equipe de especialistas de cada área passou a analisar as diferentes coleções e fazer pareceres sobre os livros inscritos..." (TIMBÓ, 2007, p. 62).

O Programa Nacional do Livro Didático (PNLD) constitui-se hoje uma das maiores políticas públicas do Brasil tanto em questão de investimento de verbas públicas ${ }^{10}$ quanto em dar acessibilidade ao livro para todos os alunos do ensino fundamental, dos mais diferentes recantos do País. A importância e a necessidade deste Programa são ressaltadas pela maioria das pessoas que participaram de nossa pesquisa, como podemos perceber na afirmação da secretária de educação de Fortaleza: "é um valioso Programa, porque garante o acesso ao livro didático que de outra forma não ocorreria!" Também conforme a fala da professora de História da EMEFM Raimundo Marque de Almeida (Quixadá): "Eu acho um Programa válido, porque é através do acesso ao livro didático que os alunos adquirem mais conhecimentos", e uma das técnicas da SMED de Quixadá: "é um Programa que precisa ser fortalecido".

Uma das mudanças no PNLD mais comentadas pelas entrevistadas foi quanto à proibição ${ }^{11}$ dos divulgadores das editoras nas escolas no período de escolha dos livros didáticos, pois a Portaria do MEC n. 2.963/2005, no seu Artigo $2^{\circ}$, expressa que é vedado aos titulares de direitos autorais e/ ou seus representantes " $\mathrm{f}$ ) realizar a divulgação dos materiais diretamente

\footnotetext{
${ }^{10}$ De acordo com o site oficial do FNDE, em 2007 "foram gastos R\$ 661 milhões no PNLD”. O que significa uma cifra considerável no investimento na educação escolar pública brasileira. Disponível em: $<$ http://www.fnde.gov.br/home/index.jsp?arquivo=livro didatico.html>. Acesso em: 28 de abril de 2009.

${ }^{11}$ Cf. Portaria n. 2.963 de 29 de agosto de 2005 (Publicação no Diário Oficial da União 167, de 30 de agosto de 2005 - Seção I página 7, que dispõe "sobre as normas de conduta para o processo de execução dos Programas do Livro". Embora esta mesma portaria ressalte "f.1) é possível a realização de orientação pedagógica, desde que realizada em até trinta dias antes da data final de escolha, apenas com a participação dos autores da obra e obrigatoriamente fora do âmbito das Escolas e das Secretarias Estaduais e Municipais de Educação".
} 
nas escolas, exceto o envio de livros e catálogos, se houver, por remessa postal". E, de acordo com o Artigo $3^{\circ}$, o não cumprimento dessa proibição implica na suspensão da participação da editora no processo de escolha.

A técnica da SME de Fortaleza ressaltou também mais uma significativa mudança no PNLD, a criação do Sistema de Controle de Remanejamento e Reserva Técnica (SISCORT), pela Resolução/ CD/FNDE n. 30, de 18 de junho de 2004, do Sistema de Controle de Remanejamento e Reserva Técnica (SISCORT), que, no Art. 1, determina que a "Reserva Técnica seja distribuída, obrigatoriamente, por intermédio do SISCORT", e no Art. 2 coloca como critério que a Reserva Técnica atenda com "complementação de livros as turmas novas e os alunos ingressantes". Principalmente, determina, no Art. 3, que esta Reserva Técnica seja "composta pelos títulos mais solicitados, por componente curricular e série...". Então, segundo a referida técnica, o SISCORT é um avanço no que diz respeito ao controle dos livros recebidos em cada escola e uma forma de efetuar o remanejamento de forma mais rápida, tendo em vista que todos os dados de livros recebidos, distribuídos e que sobraram ou faltaram ficam na rede deste Sistema de acesso público.

Em meio ao reconhecimento da importância do PNLD, foram ressaltadas, contudo, algumas dificuldades que, se solucionadas, poderiam aperfeiçoar o Programa, conforme opinião das participantes desta pesquisa.

O primeiro problema levantado pela maioria das entrevistadas foi com relação ao censo de matrícula do ano anterior, que regula a quantidade de livros a ser enviada no ano seguinte à escolha. A secretária de educação de Quixadá afirmou que esta regra causa um deficit e que o PNLD “ainda não está efetivamente $100 \%$, porque ainda não há a correção da quantidade dos livros enviados conforme o número de matrícula do ano em vigor, trabalhamos com déficit”.

Outra questão significativa que foi mencionada por uma das técnicas da SMED de Quixadá está relacionada ao atraso no envio do Guia do Livro Didático às escolas, apesar de estar disponível na internet com antecedência considerável, mas o acesso a este meio tecnológico ainda é difícil para muitas escolas, principalmente da zona rural do Estado do Ceará e, por isso, uma das técnicas sugeriu que um exemplar do Guia de Livros Didático fosse para casa de cada professor: "Não dar para fazer a 
escolha às pressas, a 'toque de caixa' para cumprir prazos, e isto precisa ser revisto pelo PNLD”.

Ressaltamos que os critérios de análise da avaliação do PNLD constam antes em Edital, ao qual as editoras têm acesso ao inscrever suas coleções para serem avaliadas. Por isso, Cerri e Ferreira (2007, p. 77) apontam que "os editais do PNLD cumprem um papel pedagógico e disciplinador para o mercado editorial". Os mesmos critérios são ressaltados posteriormente no Guia de Livros Didáticos, publicado depois de cada processo avaliativo (que ocorre a cada três anos), anexo a cada volume.

Um dos críticos contundentes à avaliação do PNLD é Munakata (2007, p. 144), quando advoga que "o sistema de avaliação e de exclusão instituído pelo Programa Nacional do Livro Didático (PNLD) reduz drasticamente a possibilidade de seleção do professor (que, não custa lembrar, pode ser capaz de dar uma ótima aula a partir de um péssimo livro)". Nessa perspectiva, nos indagamos: Por que o Governo compraria um "péssimo livro" se pode comprar os melhores? Não custa reafirmar que o PNLD avalia e aprova os livros didáticos que não ferem as legislações vigentes e que trazem conceitos gerais importantes e coerentes tanto na área histórica como pedagógica, contudo não exclui nenhum livro por sua linha conceitual e principalmente não pró́be nenhum livro de entrar no mercado capitalista. A questão emergente é que os livros que não se coadunarem com essas exigências não poderão ser comprados com as verbas públicas destinadas ao PNLD, mas podem ser comprados, por exemplo, pelas escolas privadas. A avaliação governamental das coleções didáticas livremente inscritas em edital, portanto, não impõe censura.

Portanto, faz parte da responsabilidade do MEC ficar atento para que a verba pública advinda de inúmeros impostos não seja empregada em obras duvidosas, permeadas de erros históricos, anacronismos e/ou discriminações, ou que estejam claramente "fora da lei", isto é, ferindo artigos tanto da Constituição Federal, quanto da Lei de Diretrizes e Bases da Educação (Lei n. 9.394/96), alterada pelas leis referentes à Educação Afro (Lei n. 10.639/2003) ou à Educação Indígena (Lei n. 11.645/2006), ou ainda Estatutos, como o da Criança e do Adolescente, e o do Idoso. 


\subsection{Livro didático: a escolha livre $x$ a escolha unificada}

Foi perceptível no discurso das entrevistadas em Fortaleza como um todo (tanto na esfera estadual como municipal) uma necessidade de realçar que o processo de escolha dos livros didáticos foi democrático, como sinônimo de participação plena e efetiva dos professores em cada escola, por isso, a técnica da SME de Fortaleza esclareceu que o professor escolher o livro didático é "ponto indiscutível" ${ }^{12}$. De modo especial, lembrou que já foi sugerida a escolha unificada para o município, porém esta ideia foi duramente criticada pela SME de Fortaleza, tendo em vista que escolher uma só coleção, por exemplo, de História, para todos os alunos do ensino fundamental II das escolas públicas de Fortaleza, seria, segundo ela, uma perda significativa de particularidades, e acrescentou "Já pensou $60 \mathrm{mil}$ alunos estudando todos num mesmo livro?" A técnica destacou, então, que se estaria descumprindo a essência básica do PNLD de que a escolha do livro didático precisa ser feita conforme o Projeto Político Pedagógico da escola.

No processo de escolha neste município, o primeiro passo foi uma reunião com os técnicos das Secretarias Executivas Regionais (SER's) ${ }^{13}$ para repassar as orientações do FNDE e ainda ressaltar para todos os participantes que a $2^{\mathrm{a}}$ opção deve ser tão bem pensada quanto a $1^{\text {a }}$. Esta colocação condiz com a orientação geral do FNDE, pois, no site da Organización de Estados Iberoamericanos, há trechos da fala da coordenadora-geral dos programas do livro do FNDE, Sônia Schwartz, salientando a importância da escolha do livro didático conforme o Projeto Pedagógico da escola, argumentando que "a escolha da segunda opção deve ser tão criteriosa quanto a da primeira" ${ }^{14}$.

\footnotetext{
12 Entrevista concedida à autora no dia 14 de setembro de 2007 , na sala de reunião da Secretaria Municipal de Educação de Fortaleza.

${ }^{13}$ Assim a técnica da Secretaria Municipal de Educação, que nos concedeu a entrevista para esta pesquisa, explicou: "a estrutura da rede municipal de Fortaleza cresceu muito, foram criadas as seis Secretarias Executivas Regionais, que trabalham diretamente com as escolas, pois se não fosse assim nós da Secretaria Municipal de Educação de Fortaleza não conseguiríamos acompanhar as 230 (duzentas e trinta) escolas patrimoniais" (Técnica da SME de Fortaleza).

${ }^{14}$ Disponível em: <http://www.oei.es/noticias/spip. php?article4801\&debut_5ultimasO $\mathrm{EI}=35>$. Acesso em: 01 Maio 2009.
} 
Com relação à escolha do livro didático nas escolas públicas do município de Quixadá há um diferencial com relação à capital: é uma escolha unificada. Para chegar a essa escolha, no entanto, há um longo caminho e, por isso, em entrevista, a secretária de educação de Quixadá afirmou: "A nossa escolha de livro didático tem sido muito transparente, fazemos um processo democrático" ${ }^{15}$. Também as técnicas desta Secretaria, que acompanharam todo o processo, corroboraram: "Consideramos o processo de escolha aqui em Quixadá bem democrático" ${ }^{16}$.

$\mathrm{Na}$ análise que fizemos das entrevistas com os sujeitos diretamente ligados a este processo de escolha em Quixadá17, pudemos perceber algumas justificativas que buscam legitimar a escolha unificada. De acordo com as palavras da própria secretária de educação de Quixadá, é uma necessidade que se impõe, tanto para favorecer a distribuição a todos os alunos da rede municipal, uma vez que os livros vêm conforme o censo de matrícula do ano anterior, como também para garantir a vinda da primeira opção da coleção didática que foi feita, além de "respeito" a uma tradição no município com relação à escolha do livro didático, porque a "nossa escolha do livro didático no Município de Quixadá sempre foi unificada"18. Em alguns momentos das entrevistas, vimos fragmentos paradoxais, por exemplo, a própria secretária de educação de Quixadá fez um discurso

\footnotetext{
${ }^{15}$ Entrevista concedida à autora no dia 22 de agosto de 2007, na sala de multimeios da SMED de Quixadá. Destacou: "Há municípios que quando há reunião neste período diz que não pode participar porque haverá a escolha do livro didático, mas eu digo 'eu não faço a escolha do livro didático, a escolha dos livros é feita pelos técnicos e pelos professores, eu só quero saber do resultado' (Secretária de Educação de Quixadá).

${ }^{16}$ Entrevista concedida à autora no dia 18 de setembro de 2007, na sala de multimeios da SMED de Quixadá.

${ }^{17}$ O município de Quixadá atende a uma média de 90 escolas municipais, a maioria da zona rural, espalhadas em diferentes Distritos Educacionais. De acordo com as técnicas da SMED, o aluno se desloca com muita frequência da zona rural para urbana, ou mesmo entre os Distritos da zona rural, e, na opinião delas, a escolha unificada do livro didático considera também esta questão.

18 "havia momento de termos uma única editora no município, ou seja, na época que estava no CREDE nós fazíamos mais, havia um só livro por disciplina adotado na rede pública de Quixadá, ou seja, nas escolas públicas municipais e escolas públicas estaduais. Hoje é que em virtude da municipalização cada um escolhe o seu livro, mesmo porque o Estado agora precisa se voltar mais para o ensino médio. (Secretária de Educação de Quixadá).
} 
de que "quem tem que escolher o livro que seja adequado à realidade dos alunos é o professor, porque ele é quem sabe do nível dos alunos, das dificuldades dos alunos", mas defendeu uma escolha homogeneizada para o município, acreditando realmente que o processo é democrático porque coíbe a interferência das editoras, pois pelo apresentado, a secretária chama de democrático um processo sem interferência direta das editoras e não necessariamente de atender à vontade específicas dos Distritos Educacionais e assim corre-se o risco de ser escolhida uma coleção que não atenda as especificidades de cada localidade.

Não se põe em questão aqui se é correta ou não a escolha unificada no município de Quixadá, mas uma necessária reflexão sobre até que ponto é salutar para a prática escolar do cotidiano de tantas escolas diferentes a adoção de um mesmo livro didático por disciplina, principalmente porque deixa de lado o Projeto Político Pedagógico das escolas.

Com relação às escolas da rede pública estadual de ensino em Quixadá, contudo, o processo de escolha do livro didático ocorreu de forma diferente da rede municipal. Conforme as entrevistas que realizamos com os sujeitos sociais ligados às escolas do estado naquele município, como as técnicas da Coordenadoria Regional de Desenvolvimento da Educação (CREDE 12) com sede em Quixadá, a professora responsável pelo Banco do Livro da EMEF Nemésio Bezerra, que orientou e acompanhou a escolha na escola, e a professora de História da referida escola, ficou claro que cada escola estadual teve autonomia para fazer sua escolha do livro didático.

Esse processo, entretanto, também seguiu algumas etapas. Primeiro, a supervisora técnica da CREDE 12 participou de uma oficina em Fortaleza promovida pela SEDUC. Depois esta CREDE, em um dia marcado previamente, fez uma oficina com os coordenadores das escolas estaduais que compõem a CREDE 12. Em seguida, estes assumiram a responsabilidade de multiplicar à oficina nas escolas estaduais em seus municípios $^{19}$.

${ }^{19}$ A Coordenadoria Regional de Educação - CREDE 12 - é responsável pelas escolas estaduais de oito municípios: Banabuiú, Boa Viagem, Choro, Ibaretama, Ibicuitinga, Madalena, Quixadá e Quixeramobim. 
Enfim, feita a escolha em cada escola da rede estadual de ensino do Ceará, cada uma assumiu de fato a responsabilidade de preencher o formulário de pedido via on-line e enviar, conforme faz questão de ressaltar a supervisora técnica da CREDE 12, com orgulho pelo trabalho realizado em cada escola: "dois dias antes de encerrar o prazo dado pelo MEC todas as nossas 24 escolas (sem contar os antigos anexos, que hoje chamamos de polos) já tinham feito suas escolhas, sem problema. Foi muito louvável o trabalho feito pelas escolas!".

Podemos dizer, portanto, que as escolas estaduais de Quixadá foram responsáveis por escolher os livros didáticos a serem adotados, porém percebemos um grave problema: ter garantido a autonomia de escolha em cada escola não garantiu o recebimento nem da $1^{\mathrm{a}}$ opção e nem da $2^{\mathrm{a}}$ opção, visto que na escola estadual pesquisada, em Quixadá, a coleção didática de história recebida foi a mesma da rede municipal.

\section{Os usos do livro didático no cotidiano escolar}

Nas duas escolas estaduais pesquisadas, os livros didáticos escolhidos não foram os livros recebidos para serem adotados. Assim, buscamos perceber se o fato de não terem recebido os livros escolhidos interferiu na prática no ensino de História. É bom observar que, nas apropriações de cada livro didático, "o que é necessário reconhecer são as circulações fluidas, as práticas partilhadas que atravessam os horizontes sociais" (CHARTIER, 1988, p. 134). Consideramos pertinente exemplificar de forma concreta como o livro adotado foi trabalhado em sala de aula, para, consequentemente, refletirmos sobre o ensino de História hoje.

\subsection{O livro didático nas explicações dos conteúdos nas aulas de História}

O livro didático de História que a turma do $6^{\circ}$ ano da EEFM Polivalente Modelo de Fortaleza trabalhou no ano letivo de 2008 foi História - Sociedade e Cidadania, primeiro volume de uma coleção de quatro.

Num panorama do ano letivo de 2008, com relação às explicações dos conteúdos de História na prática do "chão da sala de aula", nessa turma, conforme o período de observação direta que fizemos, podemos 
afirmar que, no primeiro semestre de história, a professora selecionava o que considerava importante dos textos principais de cada capítulo e fazia um resumo na lousa para os alunos registrarem no caderno. Depois, lia o que escrevia na lousa, sem problematizar as questões.

A maior parte do tempo da aula de História nesta turma, portanto, foi ocupado com os alunos copiando da lousa o que já estava no livro didático que receberam. $\mathrm{O}$ resumo era enorme, para dar conta do capítulo todo, que ocupava toda a lousa branca. Ressaltamos que os alunos usavam as brechas (táticas conforme Certeau) da aula para conversarem bastante entre si, apesar da postura da professora que os intimidava em geral, "utilizando-se, para isso, de algum tipo de ameaça, sutil ou explícita, proferida quando chegava à sala" (PENIN, 1994, p. 141).

Diante desse cenário, é pertinente o artigo de Gatti Júnior (2003) que fez entrevistas com professores universitários que escreveram livros didáticos, onde afirmam ter um incômodo ao saber que alguns de seus livros que têm propostas inovadoras são usados de forma tradicional. Conforme um dos autores entrevistados, por exemplo, "o professor não estava usando o livro como nós propusemos e, sim, do modo tradicional. (...) faziam com que os alunos decorassem todos os textos, como se fossem uma única coisa, avaliando, por meio das provas, se eles haviam aprendido." (GATTI JÚNIOR, 2003, p. 90).

A apropriação do livro didático de História, em especial no início e no desenvolvimento dos conteúdos nessa turma, aconteceu, portanto, como podemos perceber por meio do GRAF. 1:

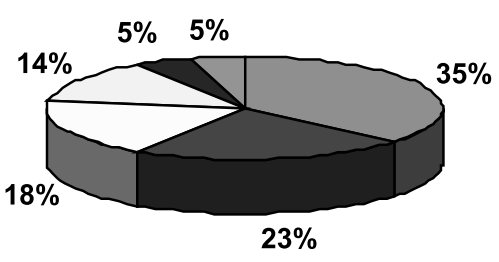

\begin{tabular}{|l|}
\hline RESUMOS \\
$\square$ QUESTIONARIOS \\
$\square$ AVALIAÇÕES \\
$\square$ CORREÇÕES AVAL. \\
$\square$ FILME \\
$\square$ RODA DECONVERSA
\end{tabular}

GRÁFICO 1: Gráfico dos usos do livro didático no início e desenvolvimento das aulas de História na turma do $6^{\circ}$ ano da EEFM Polivalente -2008

Fonte: Dados obtidos na observação direta em sala de aula durante o ano letivo de 2008 (22 semanas $=44$ aulas). 
De acordo com o GRAF. 1, podemos afirmar que as principais formas de apropriação do livro didático de História nessa turma, no momento das explicações dos conteúdos, foram mediante "Resumos", com $35 \%$ (08 semanas $=16$ aulas) e "Questionários" com 23\% (5 semanas = 10 aulas); essas duas formas perfizeram $58 \%$ do total das aulas ministradas nessa turma, o que não condiz com a afirmação inicial da professora de que trabalhava o livro didático pautado em "leituras, atividades e debates". Outras vezes, o início das aulas de História correspondeu à execução das avaliações bimestrais, com $18 \%$ ( 4 semanas $=8$ aulas), além de um filme com 5\% (01 semana $=02$ aulas $)^{20}$, relacionado com assunto abordado em sala de aula, e a nossa "Roda de Conversa" com 5\% (01 semana = 2 aulas), em que também utilizamos o livro. As demais aulas foram vivenciadas em correções das avaliações pesquisando as respostas no livro didático ${ }^{21}$, com $14 \%$ ( 3 semanas $=6$ aulas $)$.

Já a coleção adotada na turma do $6^{\circ}$ ano da EEF Nemésio Bezerra foi História Hoje, o primeiro de um total de quatro volumes destinados ao ensino fundamental II. A coleção que esta escola estadual recebeu para ser adotado como já abordamos, foi a da escolha unificada de toda a rede municipal de Quixadá.

Todos os alunos dessa turma também receberam o livro didático de História. Em geral, a professora fazia a leitura em voz alta de cada capítulo da aula e de algumas seções, como fragmentos de textos tirados da Internet, por exemplo, site da Folha de São Paulo. Pedia aos alunos para ler em voz alta o quadro "cronologia", presente em cada capítulo. À medida que os alunos liam, a professora parava de vez em quando para fazer alguma explicação mais detalhada de alguma palavra lida, mas vale destacar que, na hora da leitura, alguns alunos ficavam parados sem participar e a professora dizia "vamos pessoal, todo mundo lendo, porque eu não vou dar nota para quem não está lendo". Constatamos também que,

\footnotetext{
${ }^{20}$ Foi exibido o filme Escorpião Rei. A professora nos informou que no dia anterior passara umas questões para os alunos observarem na hora do filme.

${ }^{21}$ Em separado, a professora comentou conosco que para poder passar para o conteúdo do bimestre seguinte, é necessário que os alunos saibam bem o conteúdo trabalhado no bimestre anterior, por isso ela lhes pede para copiarem a prova, com perguntas e respostas no caderno, como "uma forma de revisar".
} 
quando os alunos são instigados a falar, eles falam sem receio de errar, pois querem participar. A professora fez muito uso de comparação, e, na medida do possível, tentou intercalar o assunto trabalhado, a ser aprendido com o que os alunos conheciam ou com o que estivesse mais próximo de sua realidade, uma maneira, conforme Rüsen (2001, p. 30), de "assenhorearse do passado, pelo conhecimento, no presente". Lembra também a zona do conhecimento proximal ${ }^{22}$ de Vygotsky (1998), entre o conhecido no cotidiano e o desconhecido a ser aprendido.

É importante relembrar que, nessa turma do $6^{\circ}$ ano, $1 / 3$ dos alunos não sabiam oficialmente ler, talvez por isso nas aulas de História a prática da leitura fosse recorrente. Portanto, a leitura coletiva ou a leitura oral da professora era uma estratégia que a docente usava com constância como podemos ver no GRAF. 2:
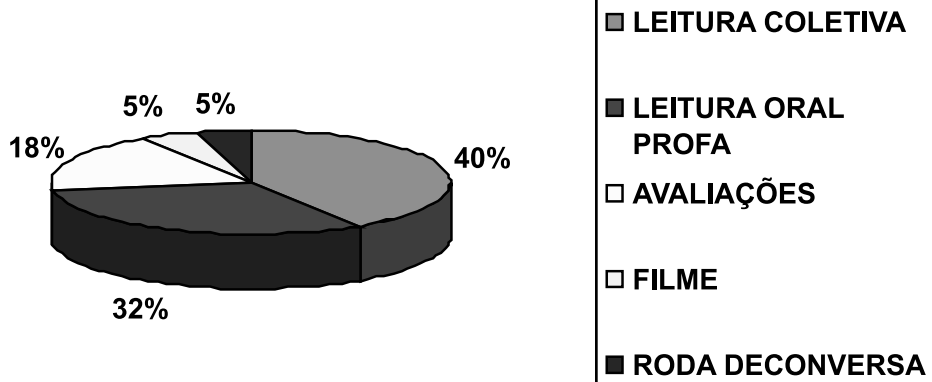

GRÁFICO 2 - Gráfico dos usos do livro didático no início e desenvolvimento das aulas de História na turma do $6^{\circ}$ ano da EEF Nemésio Bezerra

Fonte: Dados obtidos na observação direta em sala de aula durante o ano letivo de 2008 (22 semanas $=44$ aulas).

22 “A zona de desenvolvimento proximal define aquelas funções que ainda não amadureceram, mas que estão em processo de maturação, funções que amadurecerão, mas que estão em estado embrionário. Essas funções poderiam ser chamadas de 'brotos' ou 'flores' do desenvolvimento, ao invés de 'frutos' do desenvolvimento. O nível de desenvolvimento real caracteriza o desenvolvimento mental retrospectivamente, enquanto a zona de desenvolvimento proximal caracteriza o desenvolvimento mental prospectivamente" (VYGOTSKY, 1998, p. 113). 
Conforme os dados do gráfico, a exploração principal dos capítulos se deu por meio da leitura, esta era dividida em duas modalidades principais: coletiva com $40 \%$ ( 09 semanas $=18$ aulas), em que a professora lia junto com os alunos as páginas propostas, e a leitura oral por parte da professora, que lia sozinha em voz alta para os alunos acompanharem, com 32\% (07 semanas $=14$ aulas). Portanto, a leitura coletiva e a leitura oral perfizeram $72 \%$ do uso do livro didático de História nas explicações dos conteúdos durante as aulas nessa turma. Nas demais semanas, o início e o desenvolvimento das aulas foram designados para avaliações, com 18\% (04 semanas $=08$ aulas) $\mathrm{e}$ exibição de um filme $O$ Príncipe do Egito, com 5\% (01 semana = 02 aulas) e a Roda de Conversa com 5\% (01 semana $=02$ aulas).

A leitura foi a principal forma adotada no ensino de História dessa turma, mas não podemos deixar de destacar que, segundo Chartier (1988, p. 25), as práticas por meio das quais o leitor se apropria do texto são histórica e socialmente variáveis, pois "Os textos não são depositados nos objetos, manuscritos ou impressos, que o suportam como em receptáculos, e não se inscrevem no leitor como o fariam em cera mole". Assim, concordamos com Johnsen (1996, p. 134), ao afirmar que: “A pesar de todo, deberíamos poder asumir que la frecuencia y la manera de utilizar los libros de texto varía según el maestro, la matéria, el nível, la escuela, el estudiente y el hogar"23.

$\mathrm{Na}$ outra escola o livro didático de História que a turma do $6^{\circ}$ ano trabalhou no ano letivo de 2008 foi História em Documentos - Imagem e Texto, primeiro volume de uma coleção de quatro. Essa coleção didática já havia sido escolhida e adotada nessa escola no triênio anterior e novamente foi escolhida, recebida e adotada.

Apresentamos um olhar panorâmico sobre as diferentes formas de apropriação do livro didático no cotidiano escolar de uma turma que teve a oportunidade de trabalhar com o livro didático efetivamente selecionado pela professora efetiva.

As aulas do primeiro semestre com a professora efetiva, na maioria das vezes, iniciavam-se realmente com a leitura oral por parte da

\footnotetext{
${ }^{23}$ Tradução livre da autora: "Apesar de tudo, deveríamos poder assumir que a freqüência e a maneira de utilizar os livros de texto [livros didáticos] variam segundo o mestre, a matéria, o nível, a escola, o estudante e o lugar".
} 
professora, intercaladas com explicações buscando a compreensão por parte dos alunos do assunto em questão e fazia breves anotações na lousa para fixar alguma data ou conceito. A professora costumava pedir que os alunos não copiassem, mas sim que prestassem atenção às explicações. Em geral, a professora lia e interpretava o que lia para os alunos. Algumas vezes, os alunos se mostravam apáticos e desanimados, principalmente quando a professora passava mais de uma hora de explicação, uma vez que eram aulas geminadas de 50 minutos cada.

No segundo semestre, a maioria das aulas foram ministradas pelo professor substituto (também licenciado em História) e seguiram outro estilo, ou seja, primeiro ele fazia uma explicação geral do assunto na lousa com diferentes anotações, de mapas, datas e/ou fatos, depois solicitava que os alunos abrissem o livro didático e fazia a leitura em voz alta de alguns parágrafos do texto principal de cada capítulo ou pedia para algum aluno fazer. Algumas vezes que os alunos voluntariamente liam o texto em voz alta para a turma, o professor parava e explicava com outras palavras o que foi lido, fazendo uso de palavras mais do cotidiano dos alunos.

Podemos caracterizar o uso do livro didático nas explicações dos conteúdos nessa turma, depois de todas as observações feitas durante todo o ano letivo de 2008, da seguinte forma:

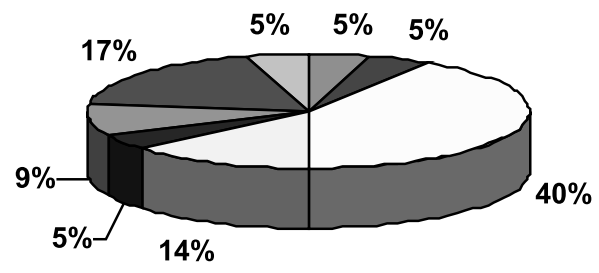

\begin{tabular}{|l|}
\hline$\square$ LEITURA SILENCIOSA \\
$\square$ LEITURA COLETIVA \\
$\square$ LEITURA ORAL PROFS \\
$\square$ LEITURA \\
PARAGRAFADA \\
$\square$ RESUMO PROF \\
$\square$ RESUMOS ALUNOS \\
$\square$ AVALIAÇÕES \\
$\square$ RODA DE CONVERSA
\end{tabular}

GRÁFICO 3 - Gráfico dos usos do livro didático no início e desenvolvimento das aulas de História na turma do $6^{\circ}$ ano da EMEIF Casimiro Montenegro

Fonte: Dados obtidos na observação direta em sala de aula durante o ano letivo de 2008 (22 semanas/dias $=44$ aulas). 
De acordo com o gráfico acima, podemos afirmar que a principal forma de apropriação do livro didático de História nessa turma, no momento da introdução e explicação dos conteúdos, foi por meio da leitura dos capítulos, sobressaindo a leitura oral feita pelos professores, com $40 \%$, (09 semanas $=18$ aulas), em segundo, a "leitura paragrafada", com 14\% $(03$ semanas $=06$ aulas $)$, em seguida a leitura silenciosa, com 5\% (01 semana $=02$ aulas $)$ e, ainda, a leitura coletiva, com 5\% (01 semana $=02$ aulas). Assim, a leitura dos textos principais de cada capítulo ocupou $64 \%$ das formas de iniciar e desenvolver as aulas de História nessa turma, no decorrer do ano letivo de 2008. Mas também o livro didático foi trabalhado por meio de resumos, tanto elaborados pelo professor, com 5\% (01 semana $=02$ aulas), quanto feitos pelos próprios alunos, com 9\% (02 semanas = 04 aulas). Ainda, as avaliações ocuparam 17\% (04 semanas $=08$ aulas $)$ e a "Roda de Conversa", 5\% (01 semana $=02$ aulas).

$\mathrm{Na}$ outra escola, a coleção adotada na turma do $6^{\circ}$ ano foi História Hoje, o primeiro volume de um total de quatro destinados ao ensino fundamental II. Esta coleção foi escolhida e recebida de forma unificada pelos professores representantes dos distritos educacionais de Quixadá que compõem a rede pública de ensino municipal como $1^{\mathrm{a}}$ opção.

Nessa turma, no início das aulas de História, a professora efetiva solicitava uma leitura paragrafada ou silenciosa dos capítulos e escrevia na lousa as páginas a serem lidas (em média 10 páginas a cada capítulo). Algumas vezes, lembrávamos-nos de Certeau (1994) com relação às "táticas e estratégias" do cotidiano, pois, talvez como tática, no momento da leitura, alguns alunos brincavam com o colega da carteira ao lado, uns faziam atividade de Ciências, visto que a aula era logo após a de História, ou uma atividade de Matemática, algumas alunas faziam desenhos e pintavam e poucos faziam de forma efetiva a leitura pedida. Às vezes, a professora usava como estratégia ameaçar os alunos de passar uma atividade mais difícil para quem estava brincando, ou colocar ponto negativo, ou chamar os pais para conversar; até mesmo chamar a coordenadora pedagógica, o que aconteceu.

Ler significa aprender História? Esta foi uma das principais indagações que nos acompanhou durante todo o período de observação nessa turma, pois ouvimos com frequência uma apologia à leitura logo no início das aulas.

Podemos resumir o exposto até aqui com o GRAF. 4: 


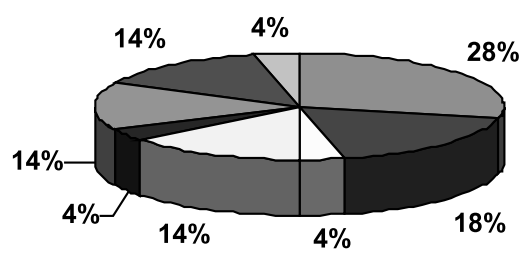

\begin{tabular}{|l}
\hline LEITURA SILENCIOSA \\
$\square$ LEITURA COLETIVA \\
$\square$ LEITURA ORAL PROFS \\
$\square$ LEITURA \\
PARAGRAFADA \\
QUESTIONARIO PROF \\
$\square$ RESUMO ALUNOS \\
$\square$ AVALIAÇÕES \\
$\square$ RODA DE CONVERSA
\end{tabular}

GRÁFICO 4 - Gráfico dos usos do livro didático no início e desenvolvimento das aulas de História na turma do $6^{\circ}$ ano da EMEFM Raimundo Marques

Fonte: Dados obtidos na observação direta em sala de aula durante o ano letivo de 2008 (28 semanas $/$ dias $=56$ aulas)

Como visualizamos melhor no GRAF. 3, as aulas de História nessa turma foram pautadas de modo especial em leitura silenciosa, 28\% das aulas (08 semanas $=16$ aulas); leitura coletiva, $18 \%(05$ semanas $=10$ aulas); leitura paragrafada, 14\% (04 semanas $=08$ aulas) e, apesar de raro, a leitura oral, com 4\% (01 semana $=02$ aulas), por parte da professora. Ao todo $64 \%$ da forma de iniciar e desenvolver as aulas de história dessa turma se pautou na leitura literal dos textos principais dos capítulos, mas essas leituras não eram antecedidas ou sucedidas por qualquer explicação do assunto, e nem ocorria durante. Às vezes, no início das aulas, foram solicitados logo resumos, com 14\% (04 semanas = 08 aulas) e questionários com 4\% (01 semana $=02$ aulas). Ainda 14\% (04 semanas $=08$ aulas $)$ dedicadas às avaliações bimestrais e 4\% (01 semana = 02 aulas) para nossa Roda de Conversa.

Poucas vezes, foi possível ver a interação entre professor, livro e aluno. Em geral, a metodologia se resumia em: alunos fazerem sozinhos a leitura, resumo ou questionário de um capítulo ${ }^{24}$ que correspondeu durante o ano letivo a $46 \%$ (leitura silenciosa $28 \%$ + resumos $14 \%$ + questionário $4 \%$ ). É útil afirmar, entretanto, que a leitura depende do real interesse dos

${ }^{24}$ A professora, em geral, só dizia o número dos capítulos e não os títulos. 
alunos em ler, pois, como lembra Chartier (1988, p. 123), “a leitura é prática criadora, atividade produtora de sentidos singulares, de significações de modo nenhum redutíveis às intenções dos autores de textos ou dos fazedores de livros...", e acrescentamos, dos professores. Fazemos questão de realçar, entretanto, que ensinar requer, além da leitura em sala de aula, uma interlocução dos professores com os alunos, no intuito de favorecer o pensar historicamente.

Diante do exposto, podemos configurar o livro didático como instrumento de aquisição da habilidade de leitura, uma bandeira levantada por muitos, como pela técnica da Secretaria de Educação de Fortaleza, que, ao nos conceder a entrevista, destacou "sou uma grande defensora do livro no processo de leitura e formação do cidadão (...). O livro é um recurso que vai tornar possível à organização da aprendizagem do aluno". Porém, como lembra Chartier (1999, p. 7-9) “a leitura é, por definição, rebelde e vadia. (...) a recepção também inventa, desloca e distorce". Assim, defendemos que, ulterior à leitura dos capítulos, as aulas de história precisam ser espaço de reflexão do que é lido para fomentar a reflexão histórica e o consequente pensar historicamente.

\subsection{Marcas que ficaram: o livro didático de história no olhar dos alunos}

No encerramento de nossa observação direta, fizemos, em cada turma, uma Roda de Conversa, ou seja, com todos os alunos sentados em círculo, realizamos entrevistas semiestruturada sobre o livro didático de História deles, perguntamos, por exemplo, se eles achavam o livro importante, o que mais gostaram, o que mais lhes chamou a atenção e o que não gostaram.

Para concluir o momento, entregamos para cada aluno uma folha de ofício com a frase Meu Livro Didático de História, solicitando que desenhassem algo que representasse o livro didático de história que estudaram e escrevessem abaixo uma frase sobre o desenho. Essa iconografia pictórica, acompanhada de uma representação textual escrita, nos ajudaria a responder à seguinte indagação: Quais as marcas deixadas pelo livro didático de história nos alunos do $6^{\circ}$ ano, de acordo com a sua representação sobre esse instrumento didático que passaram o ano utilizando nas aulas de História? 
Acreditamos que o contato que tivemos com os alunos durante as aulas de história foi primordial para que, no dia da Roda de Conversa, em cada turma e, principalmente, na hora de fazer os desenhos e as frases, cada aluno pudesse se sentir à vontade para registrar livremente as marcas que o livro didático de História imprimiu em cada um, para, em seguida, analisarmos esse material de acordo com Burke, (2004, p. 232) 25 "imagens como evidências". Acreditamos, logo, que: "O significado processado pelo tempo vivido da memória foi reelaborado, valorizando a dimensão da intertextualidade, relacionando palavras e imagens" (MAUAD e KNAUSS, 2006, p. 144).

Após a realização de todas as Rodas de Conversa, nas quatro turmas, totalizamos 112 desenhos e 95 frases que procuramos agrupar conforme suas semelhanças. Foi possível destacarmos claramente quatro temáticas que consideramos pertinentes quanto ao nosso objetivo, como podemos observar na tabela abaixo:

\section{Tabela 1}

Tabela das marcas do livro didático de História nas quatro turmas observadas em 2008

\begin{tabular}{|c|c|c|c|c|c|c|}
\hline //I// & $\begin{array}{c}\text { Valorização } \\
\text { do livro }\end{array}$ & $\begin{array}{c}\text { Valorização } \\
\text { da leitura }\end{array}$ & $\begin{array}{c}\text { Valorização do estudo/ } \\
\text { aprendizagem }\end{array}$ & $\begin{array}{c}\text { Valorização } \\
\text { de conteúdos }\end{array}$ & Outros & Total \\
\hline T1 & 04 & 05 & 02 & 06 & 02 & 19 \\
\hline T2 & 03 & 01 & 16 & 04 & 05 & 29 \\
\hline T3 & 11 & --- & 07 & 05 & 02 & 25 \\
\hline T4 & 12 & --- & 14 & 09 & 04 & 39 \\
\hline Total & 30 & 06 & 39 & 24 & 13 & $\mathbf{1 1 2}$ \\
\hline
\end{tabular}

Legenda:

$\mathrm{T} 1=$ Turma $1 /$ EEF Nemésio Bezerra

T2 = Turma 2/EMEFM Raimundo Marques

T3 = Turma 3/EMEIF Casimiro Montenegro

T4 $=$ Turma 4/EEFM Polivalente Modelo de Fortaleza

25 “A proposta essencial que este livro tenta defender e ilustrar é a de que imagens, assim como textos e testemunhos orais, constituem-se numa forma importante de evidência histórica. Elas registram atos de testemunho ocular" (BURKE, 2004, p. 17). 
Alguns alunos preferiram fazer a representação pictórica de seus pensamentos com relação à valorização do livro didático destacando respeito e amor para com ele. Os desenhos demarcaram, portanto, o olhar quanto ao significado do livro em suas vidas, embora alguns não tenham especificado ser o de História que mencionavam, mas sabiam que era esse o foco.

Outros desenhos, principalmente dos alunos da EEF Nemésio Bezerra (em que 1/3 da turma não sabia ler de forma efetiva conforme se espera nesse nível de escolarização) representaram, de modo especial, o uso do livro para ler, ou seja, a maioria dos desenhos e as frases dessa turma enfatizaram a questão da leitura, pois salientaram o quanto o livro os ajudou a ler ou favoreceu a leitura, portanto, nessa turma, as marcas que o livro deixou estão diretamente ligadas ao principal uso que foi feito do livro didático em sala de aula.

Alguns desenhos demonstram a compreensão dos alunos sobre a importância do livro didático para o ensino de História, principalmente na turma da EEFM Raimundo Marques, em Quixadá, em que esse ensino era totalmente vinculado ao livro didático. Os desenhos e as frases dessa turma remetem mais ao contato direto que os alunos tiveram com o livro no decorrer das aulas, destacando, portanto, a importância dele para o processo de ensino, pois, de modo especial, nessa turma, como vimos no capítulo anterior, "quem" realmente ensinava história era o livro didático adotado. A professora recorrentemente repetia: "tudo está no livro, é só ler".

Alguns poucos alunos salientaram, como vimos acima, dificuldades no manuseio com o livro didático de História, destacando que este poderia ser melhor ou deixando clara a dificuldade em estudar esta matéria. Essa dificuldade pode estar diretamente relacionada à forma como o livro didático foi usado.

\section{Considerações finais}

Tanto foi visto e vivido, porém escolhemos apenas alguns elementos para nos atermos ao nosso objeto, o livro didático no movimento de escolas públicas de dois municípios do Ceará.

Tanto em Fortaleza quanto em Quixadá, a importância, valorização e reconhecimento da necessidade do livro didático foram a tônica que 
permeou nossas entrevistas com gestores educacionais e professores, os quais destacaram o livro como um distintivo social. Mas percebemos também que alguns ainda veem o acesso garantido ao livro didático pelos alunos de escolas públicas de uma forma assistencialista, como se fosse um favor do governo hoje para os alunos das escolas públicas, diferente de outrora. Assim, nas análises das entrevistas, foi muito tênue a compreensão da adoção do livro didático nas escolas públicas na educação básica como um direito garantido pelas políticas públicas, que foram conquistas por meio de anos de reivindicações e lutas dos setores educacionais engajados, e, portanto um bem público necessário para uma educação mais qualitativa.

Percebemos, por parte de alguns gestores públicos e alguns professores, um desconhecimento do mais recente processo de escolha dos livros didáticos e de atual estruturação do Guia de Livros Didáticos para auxiliar na hora dessa escolha. Por exemplo, muitos ainda acreditam que existe a categorização das coleções por estrelas.

De acordo com orientação do PNLD, o Projeto Político-Pedagógico da Escola (PPP) deve orientar a escolha do livro didático que melhor se adéque à realidade da escola, porém, apesar de mencionado nas escolas pesquisadas este documento não sustentou a escolha de uma ou de outra coleção concretamente. Isso foi observado, sobretudo, no município de Quixadá, onde houve a escolha unificada, e assim o PPP de cada escola foi automaticamente desconsiderado, como se existisse um projeto coletivo de educação com relação às disciplinas escolares para todas as escolas públicas daquele município, o que não era o caso.

Outro instrumento destacado pelo PNLD como importante auxílio ao professor no processo de escolha dos livros didático é o Guia de Livros Didáticos. A princípio, também acreditávamos que este documento fosse um referencial para a escolha do livro didático, mas, apesar de se reconhecer seu valor, nas escolas em que pesquisamos esse material não foi crucial na hora da definição da coleção a ser escolhida, tendo em vista o atraso com que chegou às escolas (embora já estivesse disponível na Internet). Percebemos que, na escola estadual em Fortaleza, o Guia não estava nem presente na hora da escolha. Na escola municipal de Quixadá, embora a professora tenha nos confirmado ter tido contato prévio com o Guia, segundo as próprias técnicas da SMED de Quixadá, os exemplares do Guia só chegaram à SMED na véspera da escolha unificada. 
Quanto à escolha e distribuição dos livros didáticos pelo Fundo Nacional de Desenvolvimento da Educação(FNDE), desilusões e incertezas marcaram esse processo nas escolas públicas estaduais pesquisadas. Percebemos, nas entrevistas realizadas, uma exaltação à conquista de o professor poder escolher o livro didático com o qual deseja trabalhar, o que melhor atendesse a realidade escolar, o contexto ao qual a escola estava inserida e, em especial, ao público alvo: os alunos.

A escolha unificada para todas as escolas do município de Quixadá apresentou-se como uma solução para garantir a vinda da coleção escolhida "democraticamente" como $1^{\text {a }}$ opção. A questão é que, em nome desse objetivo, outros tão importantes, como se adequar à realidade de cada escola, foram deixados de lado. Como consequência da escolha unificada, garantiu-se o acesso dos alunos ao livro didático, mas não se garantiu a diversidade, dos Distritos Educacionais, embora seus representantes tenham afirmado que estavam com o apoio do grupo que representavam se vissem que outro livro era melhor. Portanto, questões de outra ordem, como uma boa oratória de alguns representantes, e até mesmo o contato com as resenhas do Guia de Livros Didáticos, ao qual não tiveram acesso no dia da pré-escolha, se tornaram um tanto mais relevantes do que a decisão tomada coletivamente em cada Distrito no dia da escolha final.

Com relação aos usos dos livros didáticos, destacamos que o cotidiano é uma teia relacional, cheia de acordos e conflitos, e não é possível querer ter uma realidade única do que foi observado no decorrer de um ano letivo inteiro durante as aulas de História. Podemos afirmar que, com o passar do tempo, a potencialidade mostrada pelos professores nos usos do livro didático no início da pesquisa empírica não se manteve durante o ano, e as aulas ocorreram frequentemente seguindo a mesma metodologia.

Os professores das turmas tinham diferentes formações: Pedagogia, Letras, Filosofia e História. Esta foi uma variável que só apareceu no decorrer na pesquisa de campo durante ano letivo que observamos. Apesar de ser formados em áreas diferentes, a forma como utilizaram o livro didático de História não mostrou muita diferença. Em geral sobressaiu-se o uso do livro didático pela leitura dos capítulos principais.

No início, tínhamos como hipótese e até defendemos que o professor formado em História tivesse melhores condições de explorar o 
livro didático, o que se confirmou em parte, tendo em vista os acréscimos de informações da ciência histórica que os professores formados em História ofereciam durante a explicação dos capítulos do livro usado, mas esta questão da formação não fez diferença na forma como o livro didático foi utilizado em sala de aula. Os professores no geral não usaram as demais seções que acompanhavam os textos principais de cada capítulo e muito menos as atividades propostas. A diferença se deu na concepção que estes professores tinham do que é ensinar e aprender, da responsabilidade frente aos alunos. Portanto, um ponto de chegada que nos parece muito significativo está intimamente ligado à constatação de que ser formado em História faz diferença apenas na explicação dos conteúdos de cunho historiográfico, mas não na forma como se usa o livro didático e como se percebe o aluno no processo de ensino/aprendizagem.

Ademais, todas as escolas pesquisadas tinham recursos didáticos além do livro didático disponíveis para o ensino, como TV, DVD, retroprojetor, biblioteca com mais de mil livros, laboratório de informática, contudo raramente tais recursos foram utilizados em parceria com o livro didático nas aulas de História.

Reiteramos que, nas quatro turmas, o livro didático de História atendeu às necessidades de vida prática do cotidiano da sala de aula durante as aulas de História, ou seja, oficialmente, as aulas de História aconteceram principalmente tendo como principal instrumento de ensino o livro didático. Não podemos negar, sobretudo, que, de modo especial, em três turmas, supriu os conhecimentos históricos das professoras formadas em outras áreas e sem domínio do conteúdo de História como disciplina escolar.

Nesta perspectiva, apesar de o livro didático ter melhorado visivelmente frente à forma de avaliação imposta pelo PNLD, tanto no âmbito histórico e educacional quanto no aspecto do projeto gráfico, na prática da sala de aula, muitos professores ainda o utilizam de forma parcial e limitada em suas potencialidades, apesar de este ocupar tempo central nas aulas. Assim, as mudanças no ensino de História acabam não acontecendo como o esperado na aquisição do conhecimento histórico sólido e na formação do ser humano, o que nos leva a inferir que o pensar historicamente não foi fomentado, mas reconhecemos que isto é matéria para pesquisa posterior. 
Como de certa forma já esperávamos, o livro didático, como parte da cultura material e escolar, ocupou a centralidade no cotidiano nessas turmas com as quais tivemos a oportunidade de conviver durante todo um ano letivo, porém percebemos um paradoxo: de fato ele foi supervalorizado por ocupar quase todo o tempo destinado às aulas de História, porém foi subutilizado nas suas potencialidades.

Então, faz-se fundamental e urgente uma espécie de alfabetização metodológica do olhar docente para melhor se explorar as inúmeras possibilidades de ensino com o livro didático de História e, consequentemente, enriquecerem a aprendizagem histórica com um dos recursos didáticos mais acessíveis a todos os alunos de escolas públicas.

\section{Referências}

ANDRÉ, Marli Eliza Dalmazo Afonso de. Pesquisa no Cotidiano Escolar. In: FAZENDA, Ivani. (Org.). Metodologia da Pesquisa Educacional. São Paulo: Cortez, 1991.

BOGDAN, Robert e BIKLEN, Sari. Investigação Qualitativa em Educação. Portugal: Porto Editora, 1991.

CERRI, Luís Fernando; FERREIRA, Ângela Ribeiro. Notas Sobre as Demandas Sociais de Representação e os Livros Didáticos de História. In: OLIVEIRA, Margarida Maria Dias de; STAMATTO, Maria Inês Sucupira (Org.). O Livro Didático de História: políticas educacionais, pesquisas e ensino. Natal: EDUFRN, 2007.

CERTEAU, Michael de. A Invenção do Cotidiano: 1. Artes de Fazer. Tradução de Ephraim Ferreira Alves. Rio de Janeiro: Vozes, 1994.

CHARTIER, Roger. A História Cultural: entre práticas e representações. Tradução de Maria Manuela Gallardo. Lisboa; Difel, 1990.

. A Ordem dos Livros: leitores, autores e bibliotecas na Europa entre os séculos XIV e XVIII. Tradução de Mary Del Priori. Brasília: Editora Universidade de Brasília, 1999.

CHARTIER, Roger; ROCHE, Daniel. O Livro: uma mudança de perspectiva". In: LE GOFF, Jacques; NORA, Pierre. (Org.). Fazer História: novos objetos. 4. ed. Rio de Janeiro: Francisco Alves, 1995. v. 3. 
CHOPPIN, Alain. História dos livros e das edições didáticas: sobre o estado da arte. Educação e Pesquisa, São Paulo, v.30, n. 3, p. 549-566, set./dez. 2004.

COELHO, Araci Rodrigues. Escolarização: uma perspectiva de análise dos livros didáticos da história". In: ARIAS Neto, José Miguel (Org.). Dez Anos de Pesquisas em Ensino de História. Londrina: AtritoArt, 2005.

COSTA, Ângela Maria Soares da. Prática Pedagógica e Tempo Escolar: o uso do livro didático no ensino de História. 1997. 94f. Dissertação (Mestrado em Educação) - Pontifícia Universidade Católica, São Paulo, 1997.

FUNARI, Pedro Paulo. A Renovação da História Antiga. In: KARNAL, Leandro (org.). História na Sala de Aula: conceitos, práticas e propostas. São Paulo: Contexto, 2003.

GATTI Júnior, Décio. Professores Universitários que Escrevem Livros Didáticos: análise de depoimentos de autores brasileiros contemporâneos. História e Ensino: Revista do Laboratório de Ensino de História, Londrina, v. 9, n.1, p. 63-96. 2003.

. A Escrita Escolar da História: livro didático e ensino no Brasil (1970-1990). Bauru, São Paulo: Edusc; Uberlânida: Edufu, 2004.

GRESSLER, Lori Alice. Pesquisa Educacional: importância, modelos, validade, variáveis, hipóteses, amostragem, instrumentos. 3. ed. São Paulo: Loyola, 1989.

HALLEWELL, Laurence. O Livro no Brasil: sua história. Tradução de Maria da Penha Villalobos e Lólio Lourenço de Oliveira. São Paulo: T.A. Queiroz, 1985.

JOHNSEN, Egil Borre. Libros de Texto en el Calidoscópio - estúdio crítico de la literatura y la investigación sobre los textos escolares. Barcelona: Ediciones Pomares; Corredor, S.A., 1996.

JULIA, Dominique. A Cultura Escolar como objeto histórico. REVISTA Brasileira de História da Educação. Campinas, v. 1, n. 1, p. 9-43, jan./ jun. 2001. 
LAVILlE, Christian e DIONNE, Jean. A Construção do Saber: manual de metodologia da pesquisa em ciências humanas. Tradução de Heloísa Monteiro e Francisco Settineri. Porto Alegre: Editora Artes Médicas Sul Ltda; Belo Horizonte: Editora UFMG, 1999.

LÜDKE, Menga. Pesquisa em Educação: abordagens qualitativas. São Paulo: EPU, 1986.

MAUAD, Ana Maria e KNAUSS, Paulo. Memória em Movimento: a experiência videográfica do LABHOI/UFF. História Oral: Revista da Associação Brasileira de História Oral. Rio de Janeiro, v. 9, n. 1,jan./jun. 2006. MUNAKATA, Kazumi. Produzindo Livros Didáticos e Paradidáticos. História e Filosofia da Educação. 1997. 218f. Tese (Doutorado em Educação) - Faculdade de Educação, Pontifícia Universidade de São Paulo, 1997.

OLIVEIRA, Itamar Freitas de. et al. A Ação do PNLD em Sergipe e a Escolha do Livro Didático de História (2005/2007: exame preliminar. In. OLIVEIRA, Margarida Maria Dias de; STAMATTO, Maria Inês Sucupira (Org.). O Livro Didático de História: políticas educacionais, pesquisas e ensino. Natal: EDUFRN, 2007.

OLIVEIRA, Sandra Regina Ferreira de Oliveira. Educação Histórica e a Sala de Aula: o processo de aprendizagem em alunos das séries iniciais do ensino fundamental. 2006. 274f. Tese (Doutorado em História) - Faculdade de História, Universidade de Campinas, Campinas, 2006.

PENIN, Sonia T. de Sousa. A Aula: espaço de conhecimento, lugar de cultura. Campinas, São Paulo: Papirus, 1994.

RÜSEN, Jörn. Razão Histórica: teoria da história - fundamentos da ciência história. Tradução de Estevão de Rezende Martins. Brasília: Editora Universidade de Brasília, 2001.

SPOSITO, Maria Encarnação Beltrão. Livros Didáticos de Geografia e História: avaliação e pesquisa. São Paulo: Cultura Acadêmica, 2006.

TIMBÓ, Isaíde Bandeira. O Livro Didático de História e a Formação Docente: uma reflexão necessária. In: OLIVEIRA, Margarida Maria Dias de; STAMATTO, Maria Inês Sucupira (Org.). O Livro Didático de História: políticas educacionais, pesquisas e ensino. Natal: EDUFRN, 2007. 
VIGOTSKI, Lev Semenovich. A Formação Social da Mente: o desenvolvimento dos processos psciológicos superiores. Tradução José Cipolla Neto, Luís Silveira Menna Barreto, Solange Castro Afeche. 6. Edição. São Paulo: Martins Fontes, 1998.

Data de registro: $17 / 08 / 2010$

Data de aceite: 16/02/2011 
